\title{
The Effects of Resistance Exercise With Blood Flow Restriction on Flow-Mediated Dilation and Arterial Stiffness in Elderly People With Low Gait Speed: Protocol for a Randomized Controlled Trial
}

Samuel Amorim ${ }^{1}$; Hans Degens ${ }^{2,3,4}, \mathrm{PhD}$; Alexandra Passos Gaspar ${ }^{1}, \mathrm{PhD}$; Luciana Diniz Nagem Janot De Matos ${ }^{1}$, $\mathrm{PhD}$

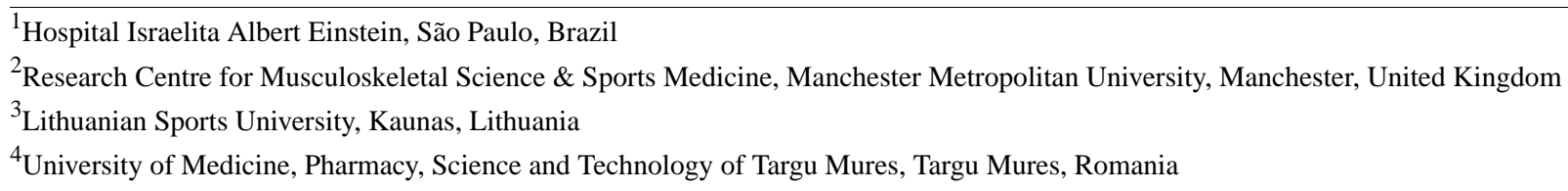

Corresponding Author:

Luciana Diniz Nagem Janot De Matos, PhD

Hospital Israelita Albert Einstein

Avenida Albert Einstein 627, Bloco D, 3 Andar

São Paulo, 05651901

Brazil

Phone: 55 (11) 21511100

Email: luciana.matos@einstein.br

\begin{abstract}
Background: During aging, a significant loss of muscle mass, strength, and power is associated with a decline in daily functional capacities. Traditionally, resistance training is prescribed to prevent or reverse the skeletal muscle weakness, but the required training intensity may be too demanding for older people with poor physical performance. Resistance exercise with blood flow moderation (KAATSU training), originally developed in Japan, combines resistance exercise with blood flow restriction. It has been reported that KAATSU training enhances muscle hypertrophy in many populations. However, few studies have evaluated the effects of resistance exercises with blood flow restriction in elderly people and how this affects vascular structure and function.

Objective: The aim of this study was to evaluate (1) the acute and chronic effects of resistance exercise with blood flow restriction on vascular health in elderly people with low gait speed and (2) whether low-load resistance training with blood flow restriction elicits similar strength and gait speed gains to those elicited by conventional resistance training without blood flow restriction.

Methods: This is an ongoing randomized controlled trial in elderly people with low gait speed. Overall, two study arms of 13 participants each perform resistance exercise with and without blood flow restriction. The 2 groups are as follows: the control group will perform conventional resistance exercise (60\% of 1 repetition maximum) and the KAATSU group will perform the low-load resistance exercise with blood flow restriction ( $20 \%$ of 1 repetition maximum) for 12 weeks. Pulse wave velocity, venous occlusion plethysmography, and flow-mediated dilation are used to assess arterial stiffness, muscle blood flow, and endothelial function, respectively. The secondary outcomes are gait speed, strength, and quality of life. All measures will be performed before and after the training program.
\end{abstract}

Results: This research study is in progress. Recruitment has started, and data collection is expected to finish in August 2020.

Conclusions: The findings of this study will have important implications for the rehabilitation of elderly people.

Trial Registration: ClinicalTrials.gov NCT03272737; https://clinicaltrials.gov/ct2/show/NCT03272737

International Registered Report Identifier (IRRID)： DERR1-10.2196/14691

(JMIR Res Protoc 2019;8(11):e14691) doi: 10.2196/14691

\section{KEYWORDS}

blood flow restriction; arterial stiffness; elderly people 


\section{Introduction}

\section{Background}

According to the World Health Organization, many countries, including China, Thailand, and Brazil, will see an increase in the percentage of the population over 65 years, from $7 \%$ in 2000 to $14 \%$ in the 2030 s [1].

This increase in the proportion of older people represents a huge challenge for health care as aging is accompanied by decrements in cardiovascular function, skeletal muscle weakness, and changes in blood coagulation, all of which have a negative impact on the functional capacity of the elderly person $[2,3]$.

Therefore, strategies that can prevent, minimize, or even reverse these effects of aging are imperative to maintain mobility and the ability to perform activities of daily living that are fundamental for the autonomy of elderly people [4].

\section{Senescence and Skeletal Muscle System}

One of the major factors contributing to the age-related muscle wasting is disuse; however, even master athletes show aging-related muscle wasting and weakness, suggesting that other factors, such as an inherent aging process, must also contribute [5].

Elderly people with muscle weakness have 2.6 times higher risk of severe mobility limitation, 4.6 times higher risk of low gait speed, and 2.1 times higher risk of mortality compared with elderly people without muscle weakness [6].

\section{Senescence and the Cardiovascular System}

Progressive loss of cardiomyocytes, reduction of the $\beta_{1}$-adrenergic response, and degenerative alterations in the sinus node are all hallmarks of the aging heart. In parallel, there is an increased deposition of collagen that will contribute to diastolic dysfunction of the heart [7].

In addition to these cardiac changes, aortic stiffness is increased and atheromatous plaques and endothelial dysfunction develop [8]. Levels of coagulation factors are elevated and those of anticoagulants are decreased, increasing the underlying incidence of thrombosis, especially above the age of 70 years $[9,10]$.

\section{Physical Exercise and the Cardiovascular System}

Many questions related to the effect of physical training on the health of older people still need to be answered, such as the most appropriate type and the best form of training to enhance functional gains without secondary vascular impairment. Aerobic training improves the cardiovascular system, increases muscle blood flow, arterial compliance, and endothelial function that reduce the risk of comorbidities [11]. However, the use of this exercise modality in elderly people with reduced gait speed is limited [12].

Resistance exercise is a potent tool to gain and maintain strength and skeletal muscle mass in sarcopenic older people with diminished gait speed $[13,14]$, but high intensities $(>60 \%$ of 1 repetition maximum $[\mathrm{RM}]$ ) are required for gains in skeletal muscle mass [15]. However, older people may not be able to cope with such loads and should avoid this type of exercise as it may cause undue stress on the cardiovascular system [16].

Recently, it was reported that low-intensity resistance exercise with blood flow restriction (BFR) may be able to induce gains in strength and muscle mass in older people [17]. Typically, BFR training uses low loads (20\%-30\% of 1RM) and short periods of training [18], a load that is better coped with and may thus be more applicable to elderly people, especially those who are sarcopenic. However, so far there are no studies evaluating the safety of BFR training for the cardiovascular system in this population [19].

\section{Study Aim and Hypotheses}

The aim of this study is to evaluate (1) the acute and chronic effects of resistance exercise with BFR on vascular health in elderly people with low gait speed and (2) whether low-load resistance training with BFR elicits similar gait speed and strength gains to those elicited by conventional resistance training without BFR. Specifically, we will investigate the effect of the 2 training modalities on arterial stiffness, muscle blood flow, endothelial function, gait speed, and muscle strength in this population.

Our hypotheses are that low-load resistance exercise with BFR elicits the same increase in strength and improvement in quality of life as conventional resistance training and that it has no detrimental effect on arterial stiffness, muscle blood flow, and endothelial function. The findings of this trial may inform future recommendations for training of the elderly population.

\section{Methods}

\section{Study Design}

This study is designed as a randomized, blind, controlled intervention trial.

\section{Ethical Approval}

The study received ethical approval from the ethical committee of the Hospital Israelita Albert Einstein and is registered on the ClinicalTrials.gov website. Participants are only included after signing the informed consent form.

Identifiable elements, including names, phone numbers, street addresses, city or state, zip code, email addresses, and date of birth will be collected but maintained under strict confidentiality. Screening materials will be kept for the participants recruited in the study and destroyed for those that do not meet the criteria or decide not to take part. Authorization for use and disclosure of the participants' personal health information is restricted to this specific study, and data will be kept for 5 years after publication.

\section{Sample Size and Power Calculation}

The sample size was calculated with Stata software (StataCorp LP) for both the acute and chronic protocols based on previous reports. It has been reported that flow-mediated dilation (FMD) was on average $4.3 \%$ (SD 3.1\%) and arterial stiffness was on average $9.2 \mathrm{~m} / \mathrm{s}(\mathrm{SD} 1.1 \mathrm{~m} / \mathrm{s})$ [20]. 
Power analysis indicated that we need 10 participants per group to detect a difference in FMD of $3.1 \%$ and arterial stiffness on average $1.1 \mathrm{~m} / \mathrm{s}$ between groups at a statistical power of 0.80 and an alpha of .05.
Owing to the conditions and frailty of elderly people, up to $20 \%$ dropouts are expected, and therefore, we are recruiting 13 participants per group.

\section{Eligibility}

The eligibility criteria for participation in the study are provided in Textbox 1 .

Textbox 1. Inclusion and exclusion criteria.

Inclusion criteria:

- $\quad$ Elderly people aged $\geq 65$ years

- Gait speed $<0.9 \mathrm{~m} / \mathrm{s}$

Exclusion criteria:

- Smoking $<6$ months

- Previous deep venous thrombosis

- Uncontrolled arterial hypertension (blood pressure $>160 / 100 \mathrm{~mm} \mathrm{Hg}$ )

- Uncontrolled dyslipidemia (total cholesterol $>220 \mathrm{mg} / \mathrm{dL}$ )

- Infections within the past 1 month

- Osteoarticular or neurological problems that prevent training

- Use of oral anticoagulants

- Symptomatic peripheral obstructive arterial disease or ankle-brachial index $<0.9$

- History of anemia, cerebrovascular disease, or myocardial infarction in the last 6 months

- Elderly people with uncontrolled diabetes mellitus or peripheral neuropathy

- Use of double antiplatelet agents: aspirin, Aggrenox, cilostazol, eptifibatide, ticlopidine, and tirofiban

\section{Participant Information and Informed Consent}

Eligible participants are recruited primarily based on the results of a gait speed test. They consult with a cardiologist and a physiatrist to assess their health and determine whether they can participate in the study. In addition, medical records of the participants will be filled in for later analysis. Eligible participants are informed of their rights, and the procedures of the study and will be allowed to participate only if they provide written informed consent. Relatives are informed about the details of the tests and exercise sessions, if necessary.

\section{Recruitment}

Participants are recruited from the Vila Mariana Unit of the Hospital Israelita Albert Einstein and elderly care centers in São Paulo.

\section{Randomization}

Using a website [21], participants are randomized into two groups, each with 13 participants:

1. Low-load resistance exercise group (20\% of $1 \mathrm{RM})$ with BFR (resistance exercise with blood flow moderation, KAATSU);

2. Conventional resistance exercise (CRE) group (60\% of 1RM).

The block sizes and randomized sequences are hidden from those who recruit or allocate participants to prevent predictability of the next assignment [22]. The participants must be aged 65 years or above.

\section{Blinding}

Research team members administering clinical assessments are blinded from participant allocation. Participant allocation will not be revealed during the study.

\section{Exercise and Training Intervention}

\section{Acute Protocol: Resistance Exercise Session}

Participants are instructed to consume a light meal before the training sessions and drink water. They should avoid physical activity and alcohol consumption 48 hours before the sessions. In addition, 24 hours before the first clinical tests, they should avoid consuming caffeine, chocolate, and tea.

Before the experimental exercise session, all participants undergo 2 familiarization sessions and 1RM tests to standardize the resistance exercise intensity. The KAATSU group participants perform bilateral seated knee extension and leg press exercises: 3 sets of 15 repetitions with 20 seconds rest between sets and 60 seconds between exercises at $20 \%$ of 1RM (Table 1). There is a 72-hour rest interval between sessions. Then, cuffs are inflated to a pressure that does not cause pain or discomfort during the warm-up and resistance exercises. This protocol is based on the study that evaluated KAATSU training in patients with metabolic diseases [23]. 
The CRE group individuals perform bilateral seated knee extension and leg press exercises: 3 sets of 15 repetitions with 60 seconds of rest between both sets and exercises, at $60 \%$ of 1RM.
Blood pressure and heart rate are evaluated before and $15 \mathrm{~min}$, $30 \mathrm{~min}$, and $60 \mathrm{~min}$ after the acute exercise session. Arterial stiffness, muscle blood flow, and vascular endothelial function are measured before and $60 \mathrm{~min}$ after the exercise session (Figure 1).

Table 1. Resistance exercise protocol of the acute study (session 1).

\begin{tabular}{|c|c|c|c|c|c|c|c|c|}
\hline Groups & Series & Repetitions & Exercises & $\begin{array}{l}\% \text { of } 1 \text { repetition } \\
\text { maximum }\end{array}$ & $\begin{array}{l}\text { Lifting cadence } \\
\text { (s) }\end{array}$ & $\begin{array}{l}\text { Interval between } \\
\text { sets (s) }\end{array}$ & $\begin{array}{l}\text { Session duration } \\
(\mathrm{min})\end{array}$ & $\begin{array}{l}\text { Cuff size } \\
(\mathrm{mm})\end{array}$ \\
\hline $\begin{array}{l}\text { Conventional resis- } \\
\text { tance exercise }\end{array}$ & 3 & 15 & $\mathrm{KE}^{\mathrm{a}}$ and $\mathrm{LP}^{\mathrm{b}}$ & 60 & $1-1^{\mathrm{c}}$ & 60 & 10 & $-^{\mathrm{d}}$ \\
\hline KAATSU & 3 & 15 & $\mathrm{KE}$ and LP & 20 & $1-1$ & 20 & 10 & 50 \\
\hline
\end{tabular}

${ }^{\mathrm{a}} \mathrm{KE}$ : knee extension.

${ }^{\mathrm{b}} \mathrm{LP}$ : leg press.

${ }^{c} 1-1: 1.0 \mathrm{~s}$ concentric and $1.0 \mathrm{~s}$ eccentric lifting cadence.

${ }^{\mathrm{d}}$ Not applicable.

Figure 1. The sequence of activities that will be developed during the acute study. AP: arterial pressure; BP: blood pressure; FMD: flow-mediated dilation; PWV: pulse wave velocity; VOP: venous occlusion plethysmography.

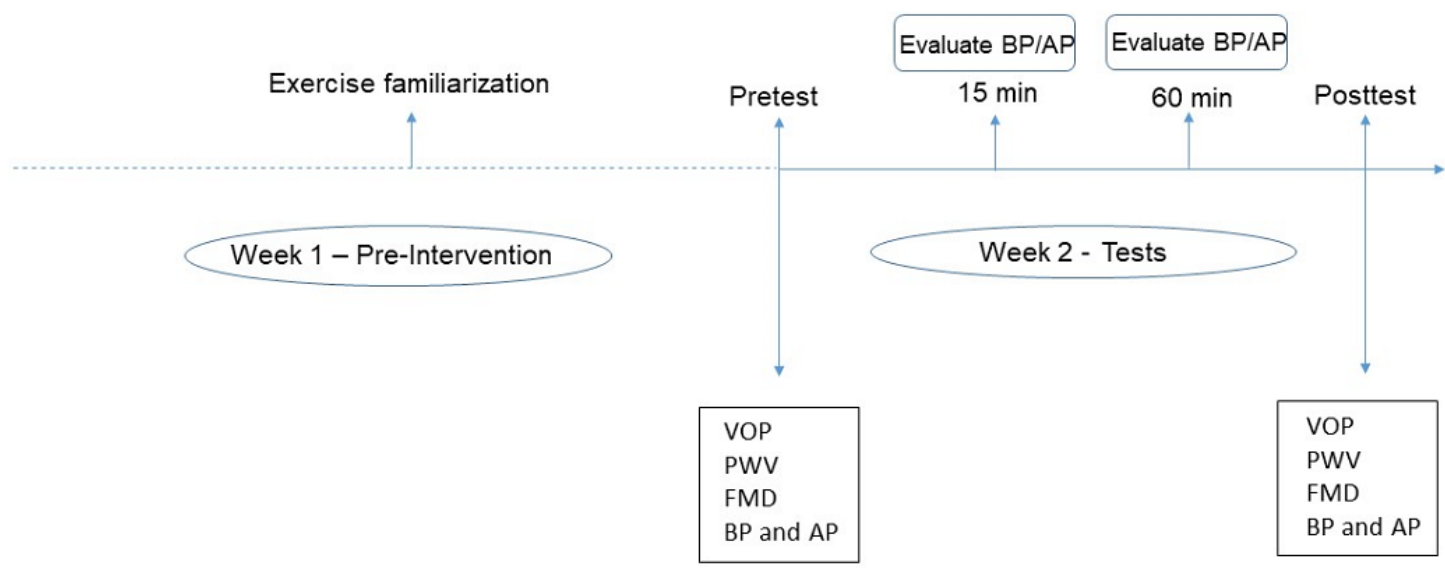

\section{Chronic Protocol: Resistance Training Program}

The protocol comprises 2 sessions per week for 12 weeks (Figure 2).

All groups are submitted to the same exercise protocol. The KAATSU group participants perform 2 sets of 15 repetitions at $20 \%$ of $1 \mathrm{RM}$ each time. The CRE group participants perform 2 sets with 15 repetitions at $60 \%$ of $1 \mathrm{RM}$ for each exercise in the first 4 weeks. The rest interval between exercises is 60 seconds for both groups, and rest interval between sets is 60 seconds for the CRE group and 20 seconds for the KAATSU group. The exercise duration of each repetition is 2.0 seconds (1.0 second concentric and 1.0 second eccentric lifting cadence). The exercise volume is increased to 3 sets for both groups in the fifth week of training. A load adjustment is carried out in training sessions 9 and 18 (Table 2). 
Figure 2. The sequence of activities that will be developed during the chronic study. AP: arterial pressure; BP: blood pressure; FMD: flow-mediated dilation; PWV: pulse wave velocity; VOP: venous occlusion plethysmography.

Resistance exercise protocol

Training period: 12 weeks (W) and Frequency: 2 times a week

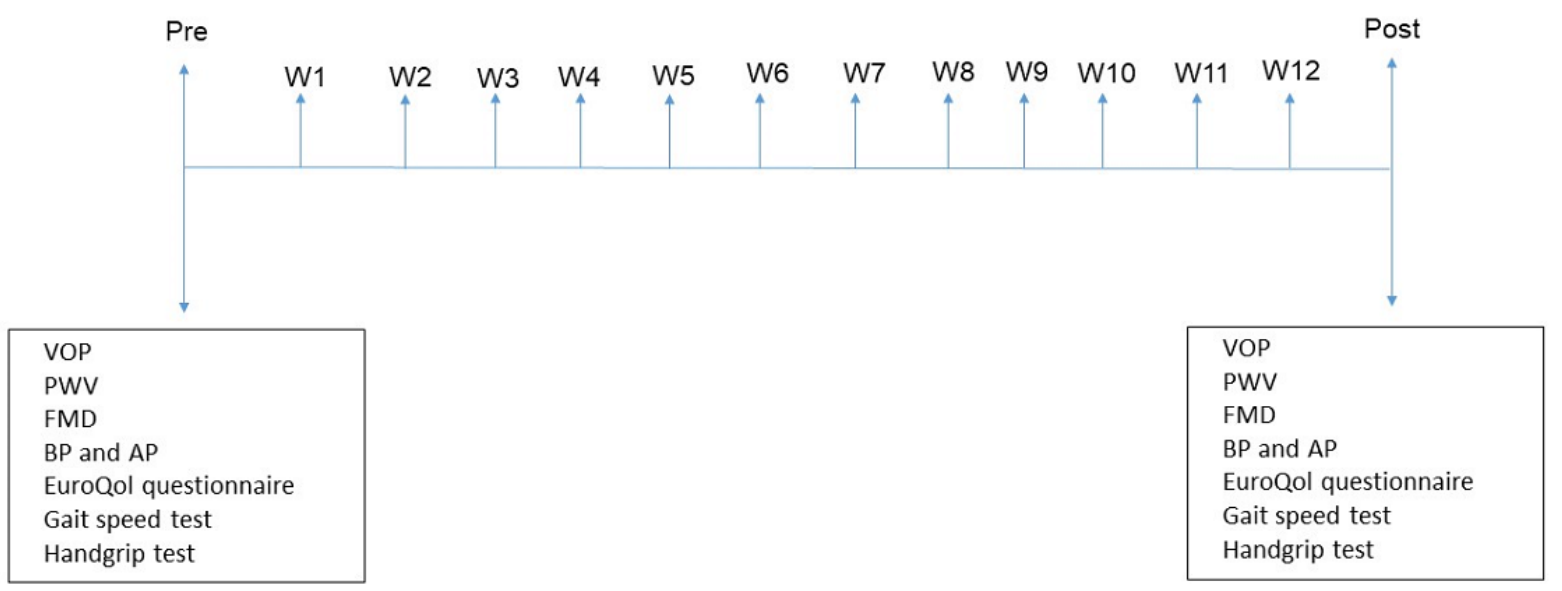

Table 2. Resistance exercise protocol of the chronic study.

\begin{tabular}{|c|c|c|c|c|c|c|c|c|c|}
\hline Sessions & Groups & Series & Repetitions & Exercises & $\%$ age of $1 \mathrm{RM}^{\mathrm{a}}$ & $\begin{array}{l}\text { Lifting cadence } \\
\text { (s) }\end{array}$ & $\begin{array}{l}\text { Interval between } \\
\text { sets (s) }\end{array}$ & $\begin{array}{l}\text { Session duration } \\
(\mathrm{min})\end{array}$ & $\begin{array}{l}\text { Cuff size } \\
(\mathrm{mm})\end{array}$ \\
\hline $1-8$ & $\mathrm{CRE}^{\mathrm{b}}$ & 2 & 15 & $\begin{array}{l}\mathrm{KE}^{\mathrm{c}} \text { and } \\
\mathrm{LP}^{\mathrm{d}}\end{array}$ & 60 & $1-1^{\mathrm{e}}$ & 60 & 10 & $-\mathrm{f}$ \\
\hline $1-8$ & KAATSU & 2 & 15 & $\mathrm{KE}$ and $\mathrm{LP}$ & 20 & $1-1$ & 20 & 10 & 50 \\
\hline 9 & $\begin{array}{l}\text { CRE and } \\
\text { KAATSU }\end{array}$ & - & - & - & $1 \mathrm{RM}$ test & - & - & - & - \\
\hline $10-17$ & CRE & 3 & 15 & $\mathrm{KE}$ and $\mathrm{LP}$ & 60 & $1-1$ & 60 & 10 & - \\
\hline $10-17$ & KAATSU & 3 & 15 & $\mathrm{KE}$ and LP & 20 & $1-1$ & 20 & 10 & 50 \\
\hline 18 & $\begin{array}{l}\text { CRE and } \\
\text { KAATSU }\end{array}$ & - & - & - & $1 \mathrm{RM}$ test & - & - & - & - \\
\hline $19-24$ & CRE & 3 & 15 & $\mathrm{KE}$ and LP & 60 & $1-1$ & 60 & 10 & - \\
\hline $19-24$ & KAATSU & 3 & 15 & KE and LP & 20 & $1-1$ & 20 & 10 & 50 \\
\hline
\end{tabular}

${ }^{\mathrm{a}} \mathrm{RM}$ : repetition maximum.

${ }^{\mathrm{b}} \mathrm{CRE}$ : conventional resistance exercise.

${ }^{\mathrm{c}} \mathrm{KE}$ : knee extension.

${ }^{\mathrm{d}} \mathrm{LP}$ : leg press.

${ }^{\mathrm{e}} 1-1: 1.0 \mathrm{~s}$ concentric and $1.0 \mathrm{~s}$ eccentric lifting cadence.

${ }^{\mathrm{f}}$ Not applicable.

\section{Determination of Blood Flow Restriction Pressure}

BFR is accomplished using the KAATSU Nano device (KAATSU Global) that automatically detects the pressure needed on the limbs to reduce blood flow.

First, baseline pressure is calculated according to the age and general physical condition of the participants. This is the pressure observed after manually tightening the pneumatic cuffs on the upper arms or upper legs. Second, the cuffs are placed around both upper limbs, and a cycle function is started that comprises 8 cycles of 20 seconds inflation and 5 seconds deflation of the cuffs. After this step, the instructor removes the cuffs and places the leg cuffs on both lower limbs and inflates the cuffs up to the optimal pressure that does not cause pain or discomfort. The optimal pressure values result from a combination of age, level of fitness, limb circumference, and tests standardized by the methodology [24]. Participants remain with the cuffs on the lower limbs from the beginning to the end of the exercise session [23].

\section{Data Management}

Data from the trial are routinely scrutinized for omissions and errors. All manually entered data are entered twice, and the source of any inconsistency is explored and resolved. Electronic data are stored and copied to an external hard drive. Data are 
only accessible to the study researchers. Each participant in the study is provided with an identification number, and the recorded data are coded using this number.

\section{Primary Goals}

\section{Venous Occlusion Plethysmography Protocol}

Muscle blood flow is evaluated with venous occlusion plethysmography. The participant's legs are elevated above the level of the heart to ensure adequate venous drainage. A mercury-filled silastic tube, connected to a low-pressure transducer and a plethysmograph (DE Hokanson), is placed around the largest circumference of the calf region. One cuff is placed around the ankle and another around the thigh. The ankle cuff is inflated to a suprasystolic pressure, 30 seconds before starting the measurements. At 15-second intervals, the cuff around the thigh is inflated above the venous pressure for a period of 7 to 8 seconds. Increased tension in the silastic tube reflects an increase in leg volume and vasodilation. The signal of the muscle blood flow wave is recorded on a polygraph and analyzed every minute, averaging 3 records per minute. The protocol is performed in a cycle of $5 \mathrm{~min}$ of rest, $3 \mathrm{~min}$ of isometric exercise, and 2 min of recovery [25].

\section{Isometric Handgrip Exercise Protocol}

In a supine position, the maximal voluntary handgrip force is determined as the highest force in 3 consecutive attempts using a Jamar hydraulic palmar dynamometer (Asimow Engineering). For the activation of the central command, mechanoreceptors, and muscular metaboreceptors, the individual performs, after 5 min of rest (baseline records), 3 min of exercise at $30 \%$ of maximal voluntary contraction. This maneuver isolates the activation of muscle metaboreceptors to observe their selective activation [26]. After the isometric handgrip exercise, there are 2 min for recovery to occur. Throughout the protocol, muscle blood flow, blood pressure, and heart rate are recorded.

\section{Measurement of Arterial Stiffness-Pulse Wave Analysis and Velocity}

Arterial stiffness is estimated from the carotid-femoral aortic pulse wave velocity [27]. The carotid-femoral aortic pulse waves are recorded by tonometry (SphygmoCor, AtCor Medical). At the same time, an electrocardiogram is registered to calculate the wave transit time. Overall, 2 distances are measured: the recording point between the carotid artery and the sternal furcula (distance 1), and between the sternal furcula and the recording point in the femoral artery (distance 2). The distance traveled by the pulse wave is calculated as distance 2-distance 1 . The carotid-femoral aortic pulse wave velocity is calculated as follows: carotid-femoral aortic pulse wave velocity $=1 / 4(\times)$ distance traveled by the pulse wave $(m) /$ transit time (seconds).

\section{Basal Blood Flow and Vasodilatory Capacity_Flow-Mediated Dilation}

Basal blood flow and flow-mediated vasodilation are measured as previously described [28,29]. Images of the brachial artery are recorded by a 2-dimensional ultrasonography device with a spectral Doppler and linear transducer (Ultra-0122, Philips).
The participant is maintained in the supine position with the arm slightly abducted, for $20 \mathrm{~min}$. After locating the brachial artery, the transducer is placed on the anteromedial aspect of the arm, perpendicular to the axis of the arm, $2 \mathrm{~cm}$ to $10 \mathrm{~cm}$ above the antecubital fold, over the artery. To confirm the location and quality of the arterial pulse obtained, Doppler is triggered. The resolution of contrast, depth, and gain is adjusted to optimize the longitudinal images of the lumen and arterial wall interface. The insonation angle is $\leq 60^{\circ}$. Blood flow velocity spectra are recorded simultaneously in the $10-\mathrm{MHz}$ linear pulse mode. The diameter of the artery and the basal blood flow are recorded continuously over 120 seconds. After the baseline recording, a cuff on the forearm is inflated to $50 \mathrm{~mm} \mathrm{Hg}$ above the systolic blood pressure. The occlusion is maintained for 5 min and then released quickly. The Doppler recordings are resumed 30 seconds before deflating the cuff and are continued for another 180 seconds. The diameter and the postocclusion blood flow are measured after release. The vasodilatory capacity is calculated as the percentage increase in the diameter of the brachial artery after occlusion.

\section{Secondary Goals}

\section{Speed Gait Test}

To measure their gait speed, participants walk $4.6 \mathrm{~m}$ and the time needed to cover this distance is recorded. The mean of 3 attempts is calculated and divided by the distance. The participants included must achieve an average of $<0.9 \mathrm{~m} / \mathrm{s}$ in the walking test [30,31].

\section{One Repetition Maximum Test (Knee Extension and Seated Leg Press)}

The dynamic force of the lower limb muscles is evaluated by the maximal repetition of knee extension and leg press exercise, according to the protocol presented in a previous study [32]. The partipants perform a warm-up comprising 1 series with 10 unloaded repetitions. After this step, the mass to be lifted is progressively increased until the maximum load that can be lifted is reached, with a maximum limit of 5 attempts and a 3 min to 5 min interval between them. The test is conducted by a physical education professional who verbally encourages the participants throughout these steps and performs the load adjustment at weeks 5 and 10 .

\section{Heart Rate and Blood Pressure}

Blood pressure and heart rate are evaluated with oscillometry (Dixtal DX 2020).

\section{Anthropometric Assessment}

Anthropometric measurements are registered before and after the training program following the International Society for Anthropometric Assessments standards [33]. Body mass is measured with an accuracy of $0.1 \mathrm{~kg}$ (Filizola). Stature is obtained by means of a stadiometer with an accuracy of $0.5 \mathrm{~cm}$. Body mass index is calculated as body mass divided by height squared. The circumference of the quadriceps is measured using a tape measure $(\mathrm{Seca})$ with a precision of $0.1 \mathrm{~cm}$. 


\section{Quality of Life EuroQol-5 Domain}

The questionnaire Quality of life Euro QoL-5 Domain s used to estimate the quality of life in participants before and after the study [34].

\section{Benefits}

The possible benefits of KAATSU training are improved muscle strength and gait speed in elderly people, without any detrimental effect on arterial stiffness, muscle blood flow, or endothelial function, and perhaps even an enhanced vascular function, all achieved at a lower training load with BFR than with conventional resistance training.

\section{Adverse Events and Risks}

BFR exercise may cause headache, red spots, redness, pain, and discomfort in lower limbs during or after exercise sessions.

\section{Auditing}

Auditing is carried out as per the policies of the sponsor and of those overseeing the sponsor.

\section{Results}

The last equipment for the study was obtained in January 2018. Recruitment and data collection were initiated in February 2018. Data collection is expected to be completed in January 2020, and the results are expected to be available in August 2020.

\section{Discussion}

\section{Overview}

This is the first time that the effects of BFR exercise on elderly people with low gait speed are evaluated utilizing the gold

\section{Acknowledgments}

The project is funded by the São Paulo Research Foundation, which is not involved in any way in this study.

\section{Authors' Contributions}

SA, APG, and LDNJDM designed the study. All authors provided methodological suggestions and took part in editing the manuscript. SA wrote the first draft, and all authors have read and approved the final version of this manuscript.

\section{Conflicts of Interest}

None declared.

\section{References}

1. World Health Organization. 2012. Good Health Adds Life to Years: Global Brief for World Health Day 2012 URL: https:/ /www.who.int/ageing/publications/whd2012 global brief/en/ [accessed 2012-01-12]

2. Kovacic JC, Moreno P, Nabel EG, Hachinski V, Fuster V. Cellular senescence, vascular disease, and aging: part 2 of a 2-part review: clinical vascular disease in the elderly. Circulation 2011 May 3;123(17):1900-1910. [doi:

10.1161/CIRCULATIONAHA.110.009118] [Medline: 21537006]

3. Park DC, Yeo SG. Aging. Korean J Audiol 2013 Sep;17(2):39-44 [FREE Full text] [doi: 10.7874/kja.2013.17.2.39] [Medline: 24653904]

4. Fielding RA, Rejeski WJ, Blair S, Church T, Espeland MA, Gill TM, LIFE Research Group. The lifestyle interventions and independence for elders study: design and methods. J Gerontol A Biol Sci Med Sci 2011 Nov;66(11):1226-1237 [FREE $\underline{\text { Full text] [doi: 10.1093/gerona/glr123] [Medline: 21825283] }}$ 
5. Piasecki M, Ireland A, Piasecki J, Degens H, Stashuk DW, Swiecicka A, et al. Long-term endurance and power training may facilitate motor unit size expansion to compensate for declining motor unit numbers in older age. Front Physiol 2019;10:449 [FREE Full text] [doi: 10.3389/fphys.2019.00449] [Medline: $\underline{\text { 31080415] }}$

6. Manini TM, Visser ÃM, Won-Park S, Patel KV, Strotmeyer ES, Chen H, et al. Knee extension strength cutpoints for maintaining mobility. J Am Geriatr Soc 2007 Mar;55(3):451-457. [doi: 10.1111/j.1532-5415.2007.01087.x] [Medline: 17341251]

7. Moore A, Mangoni AA, Lyons D, Jackson SH. The cardiovascular system. Br J Clin Pharmacol 2003 Sep;56(3):254-260 [FREE Full text] [doi: 10.1046/j.0306-5251.2003.01876.x] [Medline: 12919173]

8. Nazari-Shafti TZ, Cooke JP. Telomerase therapy to reverse cardiovascular senescence. Methodist Debakey Cardiovasc $\mathbf{J}$ 2015;11(3):172-175 [FREE Full text] [doi: 10.14797/mdcj-11-3-172] [Medline: 26634025]

9. Esmon CT. Basic mechanisms and pathogenesis of venous thrombosis. Blood Rev 2009 Sep;23(5):225-229 [FREE Full text] [doi: 10.1016/j.blre.2009.07.002] [Medline: 19683659]

10. Raskob G, Angchaisuksiri P, Blanco A, Buller H, Gallus A, Hunt B, ISTH Steering Committee for World Thrombosis Day. Thrombosis: a major contributor to global disease burden. Arterioscler Thromb Vasc Biol 2014 Nov;34(11):2363-2371. [doi: 10.1161/ATVBAHA.114.304488] [Medline: 25304324]

11. Campbell A, Grace F, Ritchie L, Beaumont A, Sculthorpe N. Long-term aerobic exercise improves vascular function into old age: a systematic review, meta-analysis and meta regression of observational and interventional studies. Front Physiol 2019;10:31 [FREE Full text] [doi: 10.3389/fphys.2019.00031] [Medline: 30863313]

12. Reid KF, Fielding RA. Skeletal muscle power: a critical determinant of physical functioning in older adults. Exerc Sport Sci Rev 2012 Jan;40(1):4-12 [FREE Full text] [doi: 10.1097/JES.0b013e31823b5f13] [Medline: 22016147]

13. Saeterbakken AH, Bårdstu HB, Brudeseth A, Andersen V. Effects of strength training on muscle properties, physical function, and physical activity among frail older people: a pilot study. J Aging Res 2018;2018:8916274 [FREE Full text] [doi: 10.1155/2018/8916274] [Medline: 29988285]

14. Gardner MM, Robertson MC, Campbell AJ. Exercise in preventing falls and fall related injuries in older people: a review of randomised controlled trials. Br J Sports Med 2000 Feb;34(1):7-17 [FREE Full text] [doi: 10.1136/bjsm.34.1.7] [Medline: 10690444]

15. Hunter GR, McCarthy JP, Bamman MM. Effects of resistance training on older adults. Sports Med 2004;34(5):329-348. [doi: 10.2165/00007256-200434050-00005] [Medline: 15107011]

16. Figueroa A, Okamoto T, Jaime S, Fahs C. Impact of high- and low-intensity resistance training on arterial stiffness and blood pressure in adults across the lifespan: a review. Pflugers Arch 2019 Mar;471(3):467-478. [doi: 10.1007/s00424-018-2235-8] [Medline: 30426247]

17. Centner C, Wiegel P, Gollhofer A, König D. Correction to: effects of blood flow restriction training on muscular strength and hypertrophy in older individuals: a systematic review and meta-analysis. Sports Med 2019 Jan;49(1):109-111. [doi: 10.1007/s40279-018-1013-2] [Medline: 30414044]

18. Horiuchi M, Okita K. Blood flow restricted exercise and vascular function. Int J Vasc Med 2012;2012:543218 [FREE Full text] [doi: 10.1155/2012/543218] [Medline: 23133756]

19. Amorim S, Gaspar AP, Degens H, de Matos LD. The effects of blood flow restriction exercise on vascular function in the elderly: a systematic review. Intergr Clin Med 2019;3(1):1-6. [doi: 10.15761/ICM.1000140]

20. Yasuda T, Fukumura K, Uchida Y, Koshi H, Iida H, Masamune K, et al. Effects of low-load, elastic band resistance training combined with blood flow restriction on muscle size and arterial stiffness in older adults. J Gerontol A Biol Sci Med Sci 2015 Aug;70(8):950-958. [doi: 10.1093/gerona/glu084] [Medline: 24917178]

21. Randomization. URL: http://randomization.com/ [accessed 2019-09-17]

22. Kim J, Shin W. How to do random allocation (randomization). Clin Orthop Surg 2014 Mar;6(1):103-109 [FREE Full text] [doi: 10.4055/cios.2014.6.1.103] [Medline: 24605197]

23. Satoh I. Kaatsu training: application to metabolic syndrome. Int J KAATSU Train Res 2011;7(1):7-12. [doi: 10.3806/ijktr.7.7]

24. KAATSU Global. 2017. KAATSU User Manual: KAATSU Protocols for Training, Recovery, Rehabilitation, Fitness, and Wellness URL: https://www.kaatsu-global.com/Assets/Files/Presentations/KAATSU User Manual.pdf [accessed 2019-09-16]

25. Wythe S, Davies T, Martin D, Feelisch M, Gilbert-Kawai E. Getting the most from venous occlusion plethysmography: proposed methods for the analysis of data with a rest/exercise protocol. Extrem Physiol Med 2015;4:8 [FREE Full text] [doi: 10.1186/s13728-015-0027-8] [Medline: 26060573]

26. Ray CA, Rea RF, Clary MP, Mark AL. Muscle sympathetic nerve responses to dynamic one-legged exercise: effect of body posture. Am J Physiol 1993 Jan;264(1 Pt 2):H1-H7. [doi: 10.1152/ajpheart.1993.264.1.H1] [Medline: $\underline{8430836]}$

27. David M, Malti O, AlGhatrif M, Al Ghatrif M, Wright J, Canepa M, et al. Pulse wave velocity testing in the Baltimore longitudinal study of aging. J Vis Exp 2014 Feb 7(84):e50817 [FREE Full text] [doi: 10.3791/50817] [Medline: 24561745]

28. Thijssen DH, Black MA, Pyke KE, Padilla J, Atkinson G, Harris RA, et al. Assessment of flow-mediated dilation in humans: a methodological and physiological guideline. Am J Physiol Heart Circ Physiol 2011 Jan;300(1):H2-12 [FREE Full text] [doi: 10.1152/ajpheart.00471.2010] [Medline: 20952670]

29. Black MA, Cable NT, Thijssen DH, Green DJ. Importance of measuring the time course of flow-mediated dilatation in humans. Hypertension 2008 Feb;51(2):203-210. [doi: 10.1161/HYPERTENSIONAHA.107.101014] [Medline: 18086954] 
30. Fried LP, Tangen CM, Walston J, Newman AB, Hirsch C, Gottdiener J, Cardiovascular Health Study Collaborative Research Group. Frailty in older adults: evidence for a phenotype. J Gerontol A Biol Sci Med Sci 2001 Mar;56(3):M146-M156. [doi: 10.1093/gerona/56.3.m146] [Medline: 11253156$]$

31. Falsarella G, Gasparotto LP, Barcelos CC, Coimbra IB, Moretto MC, Pascoa MA, et al. Body composition as a frailty marker for the elderly community. Clin Interv Aging 2015;10:1661-1666 [FREE Full text] [doi: 10.2147/CIA.S84632] [Medline: 26527868]

32. Brown LE, Weir JP. ASEP procedures recommendation I: accurate assessment of muscular strength and power. J Exerc Physiol 2001;4(3):1-21 [FREE Full text]

33. Stewart AD, Marfell-Jones M, Olds T, de Ridder JH. International Standards for Anthropometric Assessment. Australia: International Society for the Advancement of Kinanthropometry; 2001.

34. Janssen B. EuroQol. 2015. EQ-5D User Guide URL: https://euroqol.org/publications/user-guides/ [accessed 2019-09-16]

35. Shimizu R, Hotta K, Yamamoto S, Matsumoto T, Kamiya K, Kato M, et al. Low-intensity resistance training with blood flow restriction improves vascular endothelial function and peripheral blood circulation in healthy elderly people. Eur $\mathbf{J}$ Appl Physiol 2016 Apr;116(4):749-757. [doi: 10.1007/s00421-016-3328-8] [Medline: 26822582]

36. Patterson SD, Ferguson RA. Enhancing strength and postocclusive calf blood flow in older people with training with blood-flow restriction. J Aging Phys Act 2011 Jul;19(3):201-213. [doi: 10.1123/japa.19.3.201] [Medline: 21727301]

37. Yasuda T, Fukumura K, Fukuda T, Uchida Y, Iida H, Meguro M, et al. Muscle size and arterial stiffness after blood flow-restricted low-intensity resistance training in older adults. Scand J Med Sci Sports 2014 Oct;24(5):799-806. [doi: 10.1111/sms.12087] [Medline: 23730848]

\title{
Abbreviations \\ BFR: blood flow restriction \\ CRE: conventional resistance exercise \\ FMD: flow-mediated dilation \\ RM: repetition maximum
}

\author{
Edited by G Eysenbach; submitted 12.05.19; peer-reviewed by W Zhang, M Khazaee-Pool; comments to author 31.07.19; accepted \\ 07.08.19; published 01.11.19 \\ Please cite as: \\ Amorim S, Degens H, Passos Gaspar A, De Matos LDNJ \\ The Effects of Resistance Exercise With Blood Flow Restriction on Flow-Mediated Dilation and Arterial Stiffness in Elderly People \\ With Low Gait Speed: Protocol for a Randomized Controlled Trial \\ JMIR Res Protoc 2019;8(11):e14691 \\ URL: https://www.researchprotocols.org/2019/11/e14691 \\ doi: $10.2196 / 14691$ \\ PMID: $\underline{31682588}$
}

(C) Samuel Amorim Amorim, Hans Degens, Alexandra Passos Gaspar, Luciana Diniz Nagem Janot De Matos. Originally published in JMIR Research Protocols (http://www.researchprotocols.org), 01.11.2019. This is an open-access article distributed under the terms of the Creative Commons Attribution License (https://creativecommons.org/licenses/by/4.0/), which permits unrestricted use, distribution, and reproduction in any medium, provided the original work, first published in JMIR Research Protocols, is properly cited. The complete bibliographic information, a link to the original publication on http://www.researchprotocols.org, as well as this copyright and license information must be included. 